\title{
Do the feeding practices and nutrition status among HIV-exposed infants less than 6 months of age follow the recommended guidelines in Bomet County, Kenya?
}

Purity Chepkorir Lang'at ${ }^{1 *}$, Irene Awuor Ogada ${ }^{1}$, Audrey Steenbeek², Godfrey Odinga ${ }^{3}$ and Michael M. Mwachiro ${ }^{4}$

\begin{abstract}
Background: Globally, about 1.5 million pregnancies are among women living with the Human Immuno-deficiency Virus (HIV). In 2013, an estimated overall HIV prevalence of $0.34 \%$ was reported in antenatal women in Kenya, with 13,000 new HIV infections among children. Appropriate feeding practices and good nutrition status are important for the survival, growth, development and health of HIV-exposed infants, as well as the wellbeing of their mothers. The purpose of this study was to determine the feeding practices and nutrition status of HIV-exposed infants 0-5 months of age, attending the paediatric clinic in a mission hospital in Bomet County, Kenya.
\end{abstract}

Methods: This was a cross-sectional study with quantitative and qualitative techniques in data collection and analysis. A comprehensive sample of 118 mothers/caregivers with HIV-exposed infants $0-5$ months of age participated in the study. The data was analysed using SPSS software. Statistical significance was set at $p$ values less than 0.05 .

Results: Exclusive breastfeeding was practiced by the majority of the participants (73.7 \%), $14.4 \%$ practiced exclusive replacement feeding and $11.9 \%$ mixed fed their infants. More than half the infants had normal length for age (57.7\%), weight for age (60.2\%) and weight for length (76.3\%). About a third (38.1\%) of the infants were stunted, $39 \%$ were underweight and $19.5 \%$ were wasted. Infants on mixed feeding were more likely to be stunted (OR $=2.401 ; 95 \%$ Cl: $0.906-5.806 ; p=0.001)$ or underweight ( $\mathrm{OR}=2.001 ; 95 \% \mathrm{Cl}: 0.328-6.124 ; p=0.001)$ compared to those on exclusive breastfeeding. There was however, no significant difference in the likelihood for wasting among infants on exclusive breastfeeding, compared to those on exclusive replacement feeding ( $\mathrm{OR}=0.186 ; 95 \% \mathrm{Cl}$ : 0.011-3.130; $p=0.996)$ or mixed feeding ( $\mathrm{OR}=1.528 ; 95 \% \mathrm{Cl}: 0.294-7.954 ; p=0.614)$. No significant differences were observed in the likelihood for malnutrition among infants on exclusive breastfeeding, compared to those on exclusive replacement feeding.

Conclusion: Most mothers/caregivers fed their infants as recommended. The $11.9 \%$ who did not observe the recommendations were however, at risk for contracting HIV. We recommend that the Ministry of Health and National AIDS and STI Control Programme develop a policy to support infants who qualify for exclusive replacement feeding but whose mothers/caregivers face constraints in compliance.

Keywords: HIV-exposed, Infant feeding, Exclusive breastfeeding, Exclusive replacement feeding, Mixed feeding, Nutrition status, Stunting, Wasting, Underweight

\footnotetext{
* Correspondence: lapuritie@gmail.com

${ }^{1}$ School of Applied Human Sciences, Department of Food, Nutrition and

Dietetics, Kenyatta University, P.O BOX 43844-00100, Nairobi, Kenya

Full list of author information is available at the end of the article
} 


\section{Background}

Globally, about 35.3 million people are now living with the Human Immunodeficiency Virus (HIV), with women comprising more than half of this population [1]. Further, 1.5 million pregnancies are among women living with HIV, globally. In Kenya, the latest statistics indicate that there are approximately 1.6 million people living with HIV, 191,840 of them being children. The total number of deliveries by HIV positive mothers in Kenya was about 79,000, while 13,000 new HIV infections were recorded among children [2].

The World Health Organization (WHO) recommends that for HIV-exposed infants, the national health authorities should promote a single infant feeding practice as the standard of care for the prevention of mother-to-child transmission of HIV, and information about other practices be made available to mothers [3]. Kenya has adopted exclusive breast-feeding (giving infant only breast milk and no other liquids or solids except drops or syrups consisting of vitamins, minerals, or medicines) for the first 6 months after birth, introduction of appropriate complementary foods thereafter, and continued breastfeeding for the first 12 months after birth [3]. Breastfeeding should then only stop once a nutritionally adequate and safe diet can be provided without breast milk.

In circumstances where breastfeeding is not possible, exclusive replacement feeding (giving infant a suitable breast milk substitutes in the form of commercial infant formula, with no breast milk) is recommended. This exclusive replacement feeding (ERF) should be acceptable, feasible, affordable, sustainable and safe [3]. Exclusive breastfeeding (EBF) rates among all infants 0-5 months of age in Kenya has increased from $35 \%$ in 2010 to the current $61 \%$, while the rates for Bomet County are not documented [4]. There is limited literature on the EBF rates among HIV-exposed infants in particular. Scientific evidence shows that sub-optimal infant and young child feeding practices among HIV-exposed children result in malnutrition presenting as growth faltering [5-8]. As a result, growth failure as seen in stunting and underweight is considered an early marker of HIV infection [7]. The practice of EBF and ERF reduce the likelihood of mother to child transmission of HIV.

Studies have shown that in resource-limited settings, there is early occurrence of under- nutrition before the age 3 months in both HIV-infected and HIV-exposed uninfected children, with high mortality rates as well [9-12]. In Kenya, the prevalence of stunting among the general population of children less than 5 years of age is $26 \%$, underweight is at $4.3 \%$ and wasting is at $3.7 \%$, while in Bomet County, the prevalence of stunting is $35.5 \%$, underweight is $12 \%$ and wasting is $1.8 \%$ [4]. These high rates in the general population indicate that the prevalence could be higher among HIV-exposed infants. There is however, limited literature on the nutrition status of HIV-exposed infants $0-5$ months of age. This study highlights the gaps in feeding practices and nutrition status of HIV-exposed infants $0-5$ months of age and can therefore inform policy makers and implementers of areas to focus on when designing interventions for this category of children.

\section{Methods}

The purpose of the study was to determine the infant feeding practices and nutrition status of HIV-exposed infants $0-5$ months of age attending the paediatric clinic in a mission hospital in Bomet County.

\section{Study design, setting and period}

The study adopted a cross-sectional design with mixed methods (quantitative and qualitative approaches) in data collection and analysis. The study was conducted at a referral mission hospital in Bomet County. The hospital has several clinics, including one for Maternal and Child Health, where the Paediatric clinic is based. Services offered at the paediatric clinic include: growth monitoring, immunization and treatment of various childhood illnesses, as well as HIV- related care for women and children [13]. Bomet is a rural County located in the former Rift Valley Province of Kenya with a population of 730,129 as per 2009 national census [14]. The main economic activities in the county include farming for subsistence and cash, tourism and sports [14].

Data was collected for 3 months between November 2015 and January 2016.

\section{Study participants}

The target population was pairs of mothers/caregivers and infants between $0-5$ months of age born by mothers living with HIV (HIV-exposed) who were attending the paediatric clinic in the mission hospital. The mission hospital had registered 127 HIV-exposed infants 0-5 months of age during the study period. Infants born with very low birth weight (less than $1500 \mathrm{~g}$ ) as recorded in the Maternal and Child Health booklet as well as mothers/ caregivers who declined to participate were excluded from the study.

\section{Sample size and sampling techniques}

The calculated sample size was 112, based on the exclusive breastfeeding rates of $35 \%$ and a sampling frame of 127 HIV-exposed infants $0-5$ months of age in the county, at the time of the study. A further $10 \%$ was added to cater for non-response. Comprehensive sampling was then adopted in which all eligible mother/ caregiver-infant pairs were recruited (121). This is because the calculated sample size and the sampling frame were almost equal in number. 
Every consecutive mother/caregiver with a HIV-exposed infant $0-5$ months of age who consented to participate in the study was recruited once to avoid duplication of data collected. One hundred and twenty seven mothers/caregivers were eligible for the study, 121 consented while 6 declined, and therefore, 121 mothers/caregivers were recruited to participate in the study. Out of the 121 questionnaires, 118 were analysed as 3 infants had very low birth weight and thus their questionnaires were not included in the analysis. The response rate was therefore, $97.5 \%$.

Additionally, 11 key informants were interviewed. Key informants were purposively selected; all nutritionist, nurses, clinicians and adherence counsellors who provided services to the mothers living with HIV at the mission hospital's paediatric clinic. They were purposively selected because they were knowledgeable of the context specific information for mothers living with HIV registered at the health facility. For the FGDs, participants were selected using simple random sampling based on their reported mode of feeding. Two groups of 10 and 9 mothers/caregivers each were selected from those who had exclusively breastfed, 8 were selected among those who had practiced exclusive replacement feeding and 8 among those who had mixed fed.

\section{Data collection instruments and procedures}

A validated and pre-tested researcher-administered questionnaire, a Focus Group Discussion guide and a Key Informant Interviews guide were used for data collection. The questionnaire had three sections. Section A was used for recording the anthropometric data of the infant, while Section B elicited information on socio-economic characteristics of the mothers/caregivers (education, occupation and income), demographic characteristics of the mothers/ caregivers (age, marital status, religion, ethnicity, parity), infant characteristics (age and sex) and infant illness in the previous 2 weeks. Questions in the Kenya Demographic Health Survey questionnaire were adopted for this section. Section C comprised of the generic Infant and Young Child Feeding questionnaire by CARE USA (2010) [15] which applies the WHO indicators for Infant and Young Child Feeding. It elicited information on the feeding practices of the infants in the previous $24 \mathrm{~h}$ which enabled classification into exclusive breastfeeding, exclusive replacement feeding and mixed feeding. Three questions were further adopted from the World Health Organisation's indicators for assessing Infant and Young Child Feeding Practices questionnaire and added to elicit information on: time of breastfeeding initiation after birth and baby's first feed after birth (breast milk or pre-lacteal) [16]. The questionnaire was translated to Kipsigis, the native language in Bomet County, to cater for mothers/caregivers who did not understand English.
The questionnaires were researcher-administered during face to face interviews conducted with mothers/ caregivers. A total of four focus group discussions were also conducted with mothers/caregivers and the number of participants per group was $8,8,9$ and 10 respectively. The areas that were covered in the discussions included the mothers/caregivers infant feeding experiences, health services they received and challenges they faced in their choice of infant feeding. The key informant interviews were conducted with 3 nutritionists, 4 nurses, 2 clinical officers and 2 adherence counsellors who provide services to HIV-exposed infants $0-5$ months of age at the paediatric clinic. The discussions and interviews were audio tape recorded. To determine the nutrition status, anthropometric rmeasurements of weight and length were taken using the WHO recommended instruments and procedures [17].

\section{Data analysis}

Statistical analysis was conducted using Statistical Package for Social Sciences (SPSS) version 22. Infant's nutrition status was analysed using ENA for Smart software version 2011 and then exported to SPSS. Nutrition status was assessed based on the WHO 2006 growth standards Z-score cut offs for length-for-age, weightfor-age, and weight-for-length $\mathrm{z}$-scores [17]. Infant feeding practices were analysed based on the WHO and Ministry of Health recommendations for HIV-exposed infants $0-5$ months of age, and were classified as exclusive breastfeeding, exclusive replacement feeding and mixed feeding. The analysis on infant feeding was categorised into mode of feeding in the previous $24 \mathrm{~h}$ and mode of feeding since birth. The modes of feeding were defined as: Exclusive breastfeeding when infant received only breast milk and no other liquids or solids except drops or syrups consisting of vitamins, minerals, or medicines; Exclusive replacement feeding when infant received nothing else except a suitable breast milk substitutes in the form of commercial infant formula; and Mixed feeding when infant received breast milk and any other food or liquid including water, non-human milk and formula. For the mode of feeding since birth, infants who had received pre-lacteals and/ or postlacteals were classified as mixed feeding regardless of the feeding mode in the previous $24 \mathrm{~h}$. Statistical significance was set at $p<0.05$.

For qualitative data, content analysis was conducted for the Focus Group Discussions and Key Informant Interviews. The discussions and the interviews were transcribed verbatim and translated into English by the researchers. They were then read through several times by the researchers and the information from the FGDs categorized into sub-themes: experiences the mothers/ caregivers had on feeding practice chosen; challenges 
faced; and suggestions for feeding practices of HIVexposed infants. The information categories obtained in the focus group discussion analysis were used to organize the information in each key informant interview according to the informant category: nutritionist, nurses, adherence counsellors and clinical officers. Illustrative quotations were also selected from the discussions and interviews.

\section{Logistical and ethical considerations}

Ethical clearance was sought from Kenyatta University Ethical Review Committee PKU/381/E33 and Tenwek Institution Research Committee. A research permit was obtained from the National Commission for Science,
Technology and Innovation. Informed voluntary consent was sought from the mothers/caregivers and healthcare workers in form of signatures or thumb-print. Participants' privacy and confidentiality has been ensured by the use of codes rather than names.

\section{Results}

Demographic characteristics of infants and their mothers/ caregivers

There were more female infants $(54.2 \%)$, than males (45.8\%). The majority ( $45.8 \%$ ) were $2-3$ months of age, while those of $0-1$ month of age comprised $10.2 \%$ of the total study population (Table 1). The mothers/caregivers' ages in complete years ranged from 16-36 years

Table 1 Socio-economic and demographic characteristics of the mothers/caregivers

\begin{tabular}{|c|c|c|c|}
\hline \multirow[t]{2}{*}{ Characteristic } & $N=118$ & Characteristic & $N=118$ \\
\hline & \multicolumn{2}{|l|}{ Mean (SD)/ n (\%) } & n (\%) \\
\hline Age in completed years & n (\%) & Mothers/caregivers education & n (\%) \\
\hline $16-20$ & $9(7.6)$ & No education & $11(9.3)$ \\
\hline $21-29$ & $98(83.1)$ & Primary incomplete & $26(22.0)$ \\
\hline $30-36$ & $11(9.3)$ & Primary complete & $66(55.9)$ \\
\hline \multirow[t]{2}{*}{ Total } & \multirow[t]{2}{*}{$118(100.0)$} & Secondary plus & $15(12.7)$ \\
\hline & & Total & $118(100.0)$ \\
\hline \multirow[t]{2}{*}{ Mean \pm SD } & \multicolumn{3}{|l|}{$25.2 \pm 3.6$} \\
\hline & & Main Occupation & n (\%) \\
\hline Marital status & n (\%) & Casual labour & $6(5.1)$ \\
\hline Never married & $26(22.0)$ & Farmer & $27(22.9)$ \\
\hline Married & $82(69.4)$ & Salaried employment & $18(15.3)$ \\
\hline Widowed & $1(0.9)$ & Business & $17(14.4)$ \\
\hline Divorced/Separated & $9(7.7)$ & Housewife & $46(39.0)$ \\
\hline \multirow[t]{2}{*}{ Total } & \multirow[t]{2}{*}{$118(100.0)$} & Other & $4(3.4)$ \\
\hline & & Total & $118(100.0)$ \\
\hline Parity & n (\%) & & \\
\hline 1 child & $69(58.5)$ & Monthly Income (KSh.*) & n (\%) \\
\hline 2-3 children & $42(35.6)$ & $0-5,000$ & $82(69.5)$ \\
\hline 4-5 children & $7(5.9)$ & $5,001-10,000$ & $14(11.9)$ \\
\hline \multirow[t]{2}{*}{ Total } & \multirow[t]{2}{*}{ 118(100.0) } & $10,001-20,000$ & $16(13.6)$ \\
\hline & & $20,001-40,000$ & $6(5.0)$ \\
\hline Religion & n (\%) & Total & $118(100.0)$ \\
\hline Christian & 114(96.6) & & \\
\hline Muslim & $4(3.4)$ & Other income sources & n (\%) \\
\hline \multirow[t]{2}{*}{ Total } & \multirow[t]{2}{*}{ 118(100.0) } & From domestic animals & $43(36.4)$ \\
\hline & & From cash crops & $21(17.8)$ \\
\hline Relationship to the infant & n (\%) & From both domestic animals and cash crops & $44(37.3)$ \\
\hline Mothers & 114(96.6) & & \\
\hline Caregivers & $4(3.4)$ & Other asset you own like machinery and equipment & $10(8.5)$ \\
\hline Total & 118(100.0) & Total & $118(100.0)$ \\
\hline
\end{tabular}

*100 Kenyan shillings $=1$ United States dollar (USD) 
with a mean age of $25.2 \pm 3.6$ years. Most mothers/caregivers $(69.4 \%)$ were married, $22 \%$ were never married and $7.7 \%$ were either divorced or separated. More than half of the participants (58.5\%) had only 1 child, $35.6 \%$ had 2 to 3 children while $5.9 \%$ had more than 3 children. Most of the participants were the infants' mothers $(96.6 \%)$ while $3.4 \%$ were caregivers.

\section{Socio-economic characteristics of the mothers/caregivers}

More than half of the mothers/caregivers had completed primary education (55.9\%), with $9.3 \%$ having no formal education. More than a third of the participants (39\%) were housewives (Table 1). Most mothers/caregivers $(69.5 \%)$ were earning a monthly income of between 0 and 5000 Kenyan Shillings (0-50 United States Dollar); 100 Kenyan shillings $=1$ United States Dollar.

\section{Feeding practices among the infants}

From the findings, most mothers/caregivers (95.3\%) who breastfed their infants met the WHO recommendation of initiating breastfeeding within the first $1 \mathrm{~h}$ of birth (Table 2). Another positive finding was that most mothers/caregivers $(92.5 \%)$ did not give pre-lacteals upon delivery as only $7.5 \%$ reported having given prelacteals. Further, majority of the mothers (90.7 \%) had ever breast fed their infants since birth, with $89.7 \%$ having breastfed their infants in the last $24 \mathrm{~h}$. The findings show that most mothers/caregivers followed the WHO recommendations of infant feeding, as $73.7 \%$ of them exclusively breast fed their infants, while $14.4 \%$ practiced exclusive replacement feeding. Only $11.9 \%$ mixed fed their infants. All infants reported to have been breastfed were by their biological mothers as no wet nursing or use of donated breast milk was reported.

The findings from the focus group discussions and key informant interviews, were in agreement with the quantitative findings as most participants felt that all mothers should breastfeed their infants and that breastfeeding should start immediately after birth. The majority of the participants in the focus groups did not support giving other foods to the baby before initiating breastfeeding. A few felt that they needed to give a little water, 'I normally give water as it makes the throat wet and because the milk may not have started coming out yet, $\left(\mathrm{M}_{1} \mathrm{FGD}_{1}\right.$, 2015).

Exclusive breastfeeding (EBF) was practiced by most of the mothers and most of them had a positive attitude towards it. Those on EBF and exclusive replacement feeding (ERF) reported to have gotten information from the healthcare practitioners during their antenatal clinic visits. Those who breastfed said they chose to breastfeed because of its availability, requires no preparation and is nutritionally balanced. Those who chose to practice ERF however, had mixed opinions. Some chose to practice
Table 2 Breastfeeding practices since delivery

\begin{tabular}{|c|c|}
\hline \multirow[t]{2}{*}{ Practice } & \multirow{2}{*}{$\begin{array}{l}N=118 \\
\mathrm{n}(\%)\end{array}$} \\
\hline & \\
\hline \multicolumn{2}{|c|}{ Has ever been breastfed since birth $(N=118)$} \\
\hline Yes & $107(90.7)$ \\
\hline No & $11(9.3)$ \\
\hline Total & $118(100.0)$ \\
\hline \multicolumn{2}{|c|}{ Initiation of breastfeeding after delivery $(N=107)$} \\
\hline Less than $30 \mathrm{~min}$ & $66(61.7)$ \\
\hline From $30 \mathrm{~min}$ to $1 \mathrm{~h}$ & $36(33.6)$ \\
\hline More than $1 \mathrm{~h}$ & $5(4.7)$ \\
\hline Total & $107(100.0)$ \\
\hline \multicolumn{2}{|l|}{ Gave pre-lacteals $(N=107)$} \\
\hline Yes & $8(7.5)$ \\
\hline No & $99(92.5)$ \\
\hline Total & 107(100.0) \\
\hline \multicolumn{2}{|c|}{ Was breastfed in the last $24 \mathrm{~h}(\mathrm{~N}=107)$} \\
\hline Yes & $96(89.7)$ \\
\hline No & $11(10.3)$ \\
\hline Total & $107(100.0)$ \\
\hline \multicolumn{2}{|l|}{ Mode of feeding in the previous $24 \mathrm{~h}$} \\
\hline Exclusive breastfeeding & $87(73.7)$ \\
\hline Exclusive replacement feeding & $17(14.4)$ \\
\hline Mixed feeding & $14(11.9)$ \\
\hline Total & $118(100.0)$ \\
\hline \multicolumn{2}{|l|}{ Mode of feeding since birth } \\
\hline Exclusive breastfeeding & $87(73.7)$ \\
\hline Exclusive replacement feeding & $17(14.4)$ \\
\hline Mixed feeding & $14(11.9)$ \\
\hline Total & $118(100.0)$ \\
\hline
\end{tabular}

ERF because they feared transmitting the virus to the child, one of the caregivers reported choosing ERF because the mother of the infant died after delivery while another chose ERF because she was advised by a healthcare worker. Most mothers/caregivers agreed that mixed feeding was an inappropriate choice of feeding. One of the mothers/caregivers $\left(\mathrm{M}_{2} \mathrm{FGD}_{4}, 2015\right)$ said, "We are advised in the ANC clinic not to give our children any food other than breast milk before 6 months." From the key informant interviews EBF and ERF were part of the health education given at the Maternal and Child Health clinic.

\section{Nutrition status of the infants}

More than half of the infants were well nourished (normal), based on their length for age $(57.7 \%)$, weight for age $(60.2 \%)$ and weight for length $(76.3 \%)$ z-scores (Table 3). The mean length for age, weight for age and 
Table 3 Nutrition status of infants

\begin{tabular}{|c|c|c|c|c|c|c|}
\hline \multirow[t]{4}{*}{ z- scores* } & \multicolumn{2}{|c|}{ Length for age z-score } & \multicolumn{2}{|c|}{ Weight for age $z$-score } & \multicolumn{2}{|c|}{ Weight for length z-score } \\
\hline & $N=118$ & $95 \% \mathrm{Cl}$ & $N=118$ & $95 \% \mathrm{Cl}$ & $N=118$ & $95 \% \mathrm{Cl}$ \\
\hline & \multicolumn{2}{|l|}{$0-5$ months } & \multicolumn{2}{|l|}{$0-5$ months } & \multicolumn{2}{|l|}{$0-5$ months } \\
\hline & \multicolumn{2}{|l|}{$n(\%)$} & \multicolumn{2}{|l|}{$n(\%)$} & \multicolumn{2}{|l|}{$n(\%)$} \\
\hline$>2 S D$ & $5(4.2)$ & $0.8-8.5$ & $1(0.8)$ & $0.0-2.5$ & $5(4.2)$ & $0.8-8.5$ \\
\hline$\geq-1$ to $<2$ SD (Normal) & $68(57.7)$ & $48.3-66.9$ & $71(60.2)$ & $51.7-68.6$ & $90(76.3)$ & $68.6-83.9$ \\
\hline$>-3$ to $\leq-2$ SD (Moderate) & $41(34.7)$ & $25.4-44.1$ & $42(35.6)$ & $27.1-44.1$ & $23(19.5)$ & $12.7-27.1$ \\
\hline$\leq-3 \mathrm{SD}$ (Severe) & $4(3.4)$ & $0.8-6.8$ & $4(3.4)$ & $0.8-6.8$ & $0(0.0)$ & $0.0-0.0$ \\
\hline \multirow[t]{3}{*}{ Total } & 118(100.0) & - & 118(100.0) & - & $118(100.0)$ & - \\
\hline & \multicolumn{2}{|l|}{ Mean \pm SD } & \multicolumn{2}{|l|}{ Mean \pm SD } & \multicolumn{2}{|l|}{ Mean \pm SD } \\
\hline & $-0.47 \pm 1.54$ & $-0.73--0.19$ & $-0.50 \pm-0.01$ & $-0.74--0.26$ & $-0.08 \pm 1.04$ & $-0.26-0.11$ \\
\hline
\end{tabular}

* Nutrition status based on WHO 2006 growth standards z-scores

weight for length were $-0.47 \pm 1.5,-0.50 \pm-0.01$ and $-0.08 \pm 1.04$ respectively (Table 3 ).

Prevalence of morbidity in the previous 2 weeks and its association with nutrition status

Majority of the infants (90.7 \%) had not had any illness in the previous 2 weeks. Only $9.3 \%$ had fallen ill with most of them having diarrhoea (Table 4).

The likelihood of illness was analysed by nutrition indices. There was no significant association between recent illness and stunting as well as underweight (Table 5). There was however, a significantly higher likelihood of wasting among infants who had been ill in the previous 2 weeks. Infants who were ill were 20.57 times more likely to be wasted than those who were not ill.

\section{Association between nutrition status and infant feeding practices}

There was no significant difference in the likelihood of stunting and underweight among infants on exclusive breastfeeding with those on exclusive replacement feeding $(\mathrm{OR}=0.885 ; p=0.110 ; 95 \% \mathrm{CI} 0.061-2.327)$ and $(\mathrm{OR}=$

Table 4 Prevalence of morbidity in the past 2 weeks

\begin{tabular}{|c|c|}
\hline \multirow[t]{2}{*}{ Characteristic } & $N=118$ \\
\hline & n (\%) \\
\hline \multicolumn{2}{|c|}{ Illness in the previous 2 weeks $(N=118)$} \\
\hline Yes & $11(9.3)$ \\
\hline No & $107(90.7)$ \\
\hline Total & $118(100.0)$ \\
\hline \multicolumn{2}{|l|}{ Type of illness $(N=11)$} \\
\hline Diarrhoea & $7(63.6)$ \\
\hline Respiratory tract infection & $1(9.1)$ \\
\hline Fever & $2(18.2)$ \\
\hline Other & $1(9.1)$ \\
\hline Total & $11(100.0)$ \\
\hline
\end{tabular}

$0.861 ; p=0.243 ; 95 \%$ CI $0.152-4.682)$ respectively (Table 6). In contrast, infants on mixed feeding were 2.401 and 2.001 times more likely to be stunted and underweight than those on exclusive breastfeeding $(\mathrm{OR}=2.401$; $p=0.001 ; 95 \%$ CI 0.906-5.806) and (OR $=2.001 ; p=$ $0.001 ; 95 \%$ CI 0.328-6.124) respectively. There was however no significant difference in the likelihood of wasting among infants on exclusive breastfeeding with those on exclusive replacement feeding $(\mathrm{OR}=0.186 ; p=0.996 ; 95 \%$ CI $0.011-3.130)$ and on mixed feeding $(\mathrm{OR}=1.528 ; p=$ 0.614; 95 \% CI 0.294-7.954).

\section{Comparison of mean z-scores by mode of infant feeding}

The mean z-scores for weight for length, weight for age and length for age were also compared by modes of feeding. The mean weight for length $\mathrm{z}$-scores for infants on exclusive breastfeeding, exclusive replacement feeding and mixed feeding were not significantly different (ANOVA; $p=0.151$ ) (Table 7). The mean weight for age for those on mixed feeding was significantly different from those on EBF (ANOVA; $p<0.001$ ) and ERF (ANOVA; $p<0.001$ ). Those on EBF and ERF however, had no significant difference in their mean weight for age. Similar findings were observed for mean length for age z-scores.

\section{Discussion}

The findings of this study in which more infants were on exclusive breastfeeding, compared to those on exclusive replacement feeding and mixed feeding show the same trends as the Kenyan Demographic and Health Survey (KDHS) in which most infants are on EBF [4]. The KDHS however, covers data of the general population with no clear statistics on HIV specific rates of exclusive breastfeeding. Other studies with similar findings among HIV-exposed infants include a study conducted in Kisumu, Kenya, and another one in northwest 
Table 5 Likelihood of recent illness and nutrition status

\begin{tabular}{|c|c|c|c|c|c|c|c|c|c|}
\hline \multirow[t]{2}{*}{ Recent illness } & \multicolumn{3}{|c|}{ Length for age z-scores } & \multicolumn{3}{|c|}{ Weight for age $z$-score } & \multicolumn{3}{|c|}{ Weight for length z-score } \\
\hline & $\overline{\mathrm{OR}}$ & $95 \% \mathrm{Cl}$ & $P$-value & $\overline{\mathrm{OR}}$ & $95 \% \mathrm{Cl}$ & $P$-value & $\mathrm{OR}$ & $95 \% \mathrm{Cl}$ & $P$-value \\
\hline No illness reported & 1 & - & - & 1 & - & - & 1 & - & - \\
\hline Illness reported & 2.65 & $0.641-9.711$ & 0.150 & 8.75 & $2.905-15.303$ & 0.988 & 20.57 & $3.735-385.05$ & $0.005^{*}$ \\
\hline
\end{tabular}

* Significant at $p<0.05$

Ethiopia where majority of the mothers practiced exclusive breastfeeding $[18,19]$. The findings of this study were however, higher than the findings in studies conducted in India (37.2 \%) and Yobe State and Ibadan in Nigeria (21.1 and $6.2 \%$ respectively) [20-22]. HIVexposed infants who are on mixed feeds are at increased risk of contacting the HIV through breastfeeding since mixed feeding carries a greater risk of transmission because the other liquids and foods given to the baby alongside the breast milk can damage the already delicate and permeable gut wall of the infant and allow the virus to be transmitted more easily. Mixed feeding also poses the risks of contamination and diarrhea [10, 23, 24].

The findings from this study on nutrition status are in agreement with KDHS where the level of stunting in Bomet County is $35.5 \%$, underweight (12\%) and low wasting (1.8\%) [4]. Some of the possible reasons for these high levels of malnutrition could be low socioeconomic status as most of the mothers/caregivers in this study were of low socio-economic status. Similar findings were found in studies conducted in Nairobi, Kenya, where there was a drop in length for age, weight for age and weight for length $\mathrm{z}$-scores by the age of 3 weeks among HIV-exposed infants $[10,25]$. In the wider African context, studies conducted in Tanzania, South Africa and in Zambia also yielded similar results [26-28]. In contrast, the rates of stunting, underweight and wasting among HIV-exposed infants $0-6$ months of age were low in studies conducted in Tanzania and Europe [29-31]. They however, found significantly lower nutrition status as age increased. In the study conducted in Tanzania, stunting, underweight and wasting were prevalent among HIV-exposed infants at 8.7, 7.0 and 7.2 months respectively [30].

As expected, the nutrition status was better among infants who were on exclusive breast feeding and exclusive replacement feeding as recommended by WHO. The finding where most infants on exclusive breastfeeding and exclusive replacement feeding had normal nutrition status was not unique to this study. Katepa-Bwayla [32] also found that nutrition status was significantly associated with infant feeding practices in Zambia, where those on EBF were likely to have good nutrition status. Findings from studies conducted in Nairobi, and Bangladesh were also similar to the current study where infants who were not on EBF for 6 months were more likely to be underweight than those who were on EBF $[33,34]$.

In contrast, in Nigeria no significant association was found between type of feeding and HIV exposure at 6 weeks, while in Malawi, EBF was not associated with length for age, weight for age or weight for length z-scores among infants $0-6$ months $[10,35]$. Another study in Europe found neither length nor weight to be associated with HIV-exposure at birth [31]. Differences between infected and uninfected children however increased with age in this study. A randomized control trial conducted in Nairobi also found no significant difference in the nutrition status of infants on EBF and those on ERF. Stunting was however prevalent among these children at the age of 2 years [26].

The positive influence that exclusive breastfeeding and exclusive replacement feeding had on the nutrition status of infants in this study can be explained by the fact that breast milk is the best source of nourishment as it has complete nutrients and confers immunological benefits to the baby. Further, in exclusive breastfeeding, there is less exposure to unsafe water as is common in resource-limited settings, which could result in illnesses such as diarrhoea and vomiting, as well as poor nutrition status. Most women in this study were of low socio-economic status, and thus exclusive replacement feeding may not be acceptable, feasible, affordable, sustainable or safe in this setting. This study

Table 6 Association between nutrition status and infant feeding practices

\begin{tabular}{|c|c|c|c|c|c|c|c|c|c|c|c|c|}
\hline \multirow{3}{*}{ Exposure } & \multicolumn{4}{|c|}{ Stunting } & \multicolumn{4}{|c|}{ Underweight } & \multicolumn{4}{|c|}{ Wasting } \\
\hline & \multirow[t]{2}{*}{$\overline{O R}$} & \multicolumn{2}{|l|}{$\mathrm{Cl}(95 \%)$} & \multirow[t]{2}{*}{$P$-value } & \multirow[t]{2}{*}{$\overline{O R}$} & \multicolumn{2}{|l|}{$\mathrm{Cl}(95 \%)$} & \multirow[t]{2}{*}{$P$-value } & \multirow[t]{2}{*}{$\overline{O R}$} & \multicolumn{2}{|l|}{$\mathrm{Cl}(95 \%)$} & \multirow[t]{2}{*}{$P$-value } \\
\hline & & Lower limit & Upper limit & & & Lower limit & Upper limit & & & Lower limit & Upper limit & \\
\hline EBF & 1 & - & - & - & 1 & - & - & - & 1 & - & - & - \\
\hline ERF & 0.885 & 0.061 & 2.327 & 0.110 & 0.861 & 0.152 & 4.682 & 0.243 & 0.186 & 0.011 & 3.130 & 0.996 \\
\hline MF & 2.401 & 0.906 & 5.806 & $0.001^{*}$ & 2.001 & 0.328 & 6.124 & $0.001^{*}$ & 1.528 & 0.294 & 7.945 & 0.614 \\
\hline
\end{tabular}

* Significant at $p<0.05$ 
Table 7 Comparison of mean z-scores by mode of infant feeding

\begin{tabular}{lllll}
\hline Variable & EBF & ERF & MF & ANOVA \\
& $(n=87)$ & $(n=17)$ & $(n=14)$ & $P$ value \\
\hline Mean LAZ \pm SD & $-0.18 \pm 1.3_{\mathrm{a}}$ & $-0.54 \pm 1.6_{\mathrm{a}}$ & $-0.47 \pm 1.5_{\mathrm{b}}$ & $<0.001^{*}$ \\
Mean WAZ \pm SD & $-0.29 \pm 1.0_{\mathrm{a}}$ & $-0.25 \pm 1.14_{\mathrm{a}}$ & $-2.1 \pm 1.4_{\mathrm{b}}$ & $<0.001^{*}$ \\
Mean WLZ \pm SD & $-0.11 \pm 0.8 \mathrm{a}$ & $0.348 \pm 1.5 \mathrm{a}$ & $-0.33 \pm 1.3_{\mathrm{a}}$ & 0.151
\end{tabular}

* Significant at $p<0.05$

aThere was no statistical difference between the means

bThe mean was statistically different from the other means

adds to the existing evidence that exclusive breastfeeding promotes good nutrition status among HIV-exposed infants. It therefore, supports the recommendations by WHO and Kenya's Ministry of Health.

\section{Limitation of the study}

The study did not reveal the influence that time or different seasons in the year may have on infant feeding practices, as well as the changes in feeding practices that may occur with infant age, as this information was only collected at one point in time. The sample size was also limited due to the small sampling frame and the target population which was HIV-exposed infants 0-5 months of age. The study therefore adopted a comprehensive sample in which all those who met the inclusion criteria participated in the study.

\section{Conclusion}

Most participants followed the recommended feeding practice (exclusive breastfeeding or exclusive replacement feeding). Mixed feeding was recorded for $11.9 \%$, implying that this population is at a higher risk for mother to child transmission of HIV as well as malnutrition and other childhood illness such as diarrhoea and upper respiratory tract infections. More than a third of the infants were chronically malnourished, with a fifth acutely malnourished. Mixed feeding increased the likelihood for malnutrition. We recommend that the Kenya Ministry of Health and National AIDS and STI Control Programme develop a policy to support infants who qualify for exclusive replacement feeding but whose mothers/ caregivers face constraints in complying.

\section{Abbreviations}

EBF, exclusive breast feeding; ERF, exclusive replacement feeding; HIV, Human Immunodeficiency Virus; IYCF, infant and young child feeding; LAZ, length-for-age Z-scores; WAZ, weight-for-age Z-scores; WHO, World Health Organization; WLZ, weight-for-length Z-scores

\section{Acknowledgment}

We would like to acknowledge the assistance of Mr. Joseph Waitara who assisted in the data analysis.

\section{Funding}

The study was funded by the authors.

\section{Availability of data and materials}

The authors will not share the data because the health facility has not granted permission for use in repositories.

\section{Authors' contributions}

PCL: initiation of the study, design, implementation and writing. IAO: design, implementation, analysis and writing. AS: implementation and CO- writing. GO: critique and writing. MM: critique and writing. All authors read and approved the final manuscript.

\section{Competing interests}

The authors declare no competing interests.

\section{Consent for publication}

Not applicable.

\section{Ethics approval and consent to participate}

Ethical clearance for the study was sought from Kenyatta University Ethical Review Committee number PKU/381/E33 and Tenwek Institution Research Committee. A research permit was obtained from the Kenyan National Commission for Science, Technology and Innovation. Voluntary informed consent was sought from all mothers/caregivers and healthcare workers in form of signatures or thumb-prints. Those who declined to participate were excluded from the study. Participants' privacy and confidentiality has been ensured by the use of codes rather than names.

\section{Author details}

${ }^{1}$ School of Applied Human Sciences, Department of Food, Nutrition and Dietetics, Kenyatta University, P.O BOX 43844-00100, Nairobi, Kenya. ${ }^{2}$ School of Nursing and Department of Community Health and Epidemiology, Dalhousie University, 3869 University Avenue, Nova scotia, Canada. ${ }^{3}$ School of Tourism, Hospitality and Events Management, Department of Tourism Management, Moi University, P.O.BOX. 3900-0301, Eldoret, Kenya. ${ }^{4}$ General Surgery Department, Tenwek Hospital, P.O Box 39-20400, Bomet, Kenya.

Received: 1 April 2016 Accepted: 2 July 2016

Published online: 13 July 2016

\section{References}

1. UNAIDS. Global AIDS response progress reporting 2014. 2014

2. NASCOP. Kenya AIDS Indicator Survey 2012. 2014. (Vol. 66 Suppl 1). Retrieved from http://www.ncbi.nlm.nih.gov/pubmed/24732813. doi:10. 1097/QAl.0000000000000152. Accessed March 2015.

3. WHO, UNICEF, UNAIDS, UNFPA. Guidelines on HIV and Infant Feeding: Principles and recommendations for infant feeding in the context of HIV and summary of evidence. Geneva: World Health Organization; 2010. p. 149. Retrieved from http://apps.who.int/iris/bitstream/10665/44345/1/ 9789241599535_eng.pdf. Accessed March 2015.

4. KNBS, MOH, NACC, KEMRI, NCPD. Kenya demographic and health survey: Key indicators. 2015

5. Bii SC, Otieno-Nyunya B, Siika A, Rotich JK. Infant feeding practices among HIV infected women receiving prevention of mother-to-child transmission services at Kitale District Hospital, Kenya. East Afr Med J. 2008;85(4):156-61. http://doi.org/10.4314/eamj.v85i4.9639. Accessed March 2015.

6. Kimani-Murage EW, Norris SA, Pettifor JM, Tollman SM, Klipstein-Grobusch K, Gómez-Olivé XF, Kahn K. Nutritional status and HIV in rural South African children. BMC Pediatr. 2011;11(1):23. http://www.biomedcentral.com/14712431/11/23. Accessed March 2015.

7. Neri D, Somarriba G, Schaefer N, Aida C. Growth and body composition of uninfected children exposed to HIV: Comparison with a contemporary cohort and US national standards. J Pediatr. 2013;163(1):249-54.

8. Oleske J. Lont-term outcomes in infants born to HIV-infected women. J Acquir Immune Defic Syndr. 2008;32(3):353-73.

9. Homsy J, Moore D, Barasa A, Were W, Likicho C, Waiswa B. Breastfeeding, mother-to-child HIV transmission, and mortality among infants born to HIV-infected women on highly active antiretroviral therapy in Rural Uganda. J Acquir Immune Defic Syndr. 2010;53:28-35.

10. Kafulafula G, Hoover DR, Taha TE, Thigpen M, Li Q, Fowler MG. Frequency of gastroenteritis and gastroenteritis-associated mortality with early weaning in HIV-1-uninfected children born to HIV-infected women in Malawi. J Acquir Immune Defic Syndr. 2010;53:6-13. 
11. Kuhn L, Sinkala M, Semrau K, Kankasa C, Kasonde P, Mwiya M, Aldrovandi GM. Elevations in mortality associated with weaning persist into the second year of life among uninfected children born to HIV-infected mothers. Clin Infect Dis. 2010;50(3):437-44. http://doi.org/10.1086/649886. Accessed March 2015.

12. Ram M, Gupte N, Nayak U, Kinikar AA, Khandave M, Shankar AV, Gupta A. Growth patterns among HIV-exposed infants receiving nevirapine prophylaxis in Pune, India. BMC Infect Dis. 2012;12(1):282. http://doi.org/10.1186/1471-2334-12-282. Accessed March 2015.

13. Hospital T. Tenwek Hospital Strategic plan 2014-2018. 2013.

14. Bomet County Website (2016) Retrieved on February 3, 2016, from http://www.bomet.go.ke. Accessed March 2015.

15. CARE USA. Generic Infant and Young Child Feeding questionnaire. 2010. Retrieved on November 3, 2014 from http://www.ennonline.net/iycfdataguide. Accessed March 2015.

16. World Health Organization (WHO). Indicator for assessing infant and young child feeding practices: Part II. 2010.

17. World Health Organization (WHO). (2006). WHO child growth standards The Lancet (Vol. 371). Retrieved from http://www.thelancet.com/pdfs/ journals/lancet/PIIS0140-6736(08)60131-2.pdf. Accessed March 2015.

18. Okanda JO, Borkowf CB, Girde S, Thomas TK, Lecher S. Exclusive breastfeeding among women taking HAART for PMTCT of HIV-1 in the Kisumu Breastfeeding Study. BMC Pediatr. 2014;14(1):280. http://www.ncbi. nlm.nih.gov/pubmed/25380718. Accessed March 2015.

19. Muluye D, Woldeyohannes D, Gizachew M, Tiruneh M. Infant feeding practices and associated factors of HIV positive mothers attending prevention of mother to child transmission and antitetroviral therapy clinics in Gondar Town health institutions, Northwest Ethiopia. BMC Public Health. 2012;240(12). http://www.biomedcentral.com/1471-2458/12/240.

20. Khan AM, Kayina P, Agrawal P, Gupta A, Kannan AT. A study on infant and young child feeding practices among mothers attending an urban health center in East Delhi. Indian J Public Health. 2012;56(4):301-4. http://www. ijph.in/text.asp?2012/56/4/301/106420. Accessed March 2015.

21. Ajibuah J. Appraisal of Nursing Mother's Knowledge and Practice of Exclusive-Breastfeeding Yobe State Nigeria. Biology, Agriculture and Health, 3. 2013. Retrieved from http://www.cmamforum.org/Pool/Resources/Nursingmothers-exclusive-breastfeeding-Yobe-State-Nigeria.pdf. Accessed March 2015.

22. Oladokun RE, Brown BJ, Osinusi K. Infant-feeding pattern of HIV-positive women in a prevention of mother-to-child transmission (PMTCT) programme. AIDS Care. 2010;22(9):1108-14. http://doi.org/10.1080/ 09540120903511008. Accessed March 2015.

23. UNICEF. HIV and Infant Feeding. 2005. Retrieved on May 2, 2016 from http://www.unicef.org/nutrition/index_24827.html. Accessed March 2015.

24. Coovadia HM, Rollins NC, Bland RM, Little K, Coutsoudis A, Bennish ML, Newell M. Mother-to-child transmission of HIV-1 infection during exclusive breastfeeding in the first 6 months of life: an intervention cohort study. Lancet. 2007:369(1):107-16.

25. Sherry B, Embree J, Mei Z. Sociodemographic charactiristics, care, feeding practices and growth of cohorts of cohorts of chilren bornto HIV-1 seropositive and seronegative mothers in Nairobi, Kenya. Trop Med Int Health. 2000;5:678-89.

26. McGrath C, Nduati R, Richardson BA, Kristal AR, Mbori-Ngacha D, Farquhar C, John-Stewart GC. The prevalence of stunting is high in HIV-1-exposed uninfected infants in Kenya. J Nutr. 2012;142(4):757-63. http://doi.org/10.3945/jn.111.148874.

27. Ramokolo V, Lombard C, Fadnes LT, Doherty T, Jackson DJ, Goga AE, Van den Broeck J. HIV infection, viral load, low birth weight, and nevirapine are independent influences on growth velocity in HIV-exposed South African infants. J Nutr. 2014;144(1):42-8. http://jn.nutrition.org/content/144/1/42.long. Accessed March 2015.

28. Makasa M, Kasonka L, Chisenga M, Sinkala M, Chintu C, Tomkins A, Filteau S. Early growth of infants of HIV-infected and uninfected Zambian women. Trop Med Int Health. 2007;12:594-602. http//doi.org/10.1111/j.1365-3156.2007.01836.x. Accessed March 2015.

29. Webb AL, Manji K, Fawzi WW, Villamor E. Time-independent maternal and infant factors and time-dependent infant morbidities including HIV infection, contribute to infant growth faltering during the first 2 years of life. J Trop Pediatr. 2009;55(2):83-90. http://www.ncbi.n/m.nih.gov/pmc/articles/ PMC2734313/. Accessed March 2015.

30. Mcdonald CM, Kupka R, Manji KP, Bosch RJ, Aboud S, Kisenge R. Predictors of stunting, wasting and underweight among Tanzanian children born to HIV-infected women. Eur J Clin Nutr. 2012;66(11):1265-76. http://www.ncbi. nlm.nih.gov/pubmed/23031850. Accessed March 2015.
31. Newell M-L, Borja MC, Peckham C. Height, weight, and growth in children born to mothers with HIV-1 infection in Europe. Pediatrics. 2003;111(1):e52-60. http://www.ncbi.nlm.nih.gov/pubmed/12509595. Accessed March 2015.

32. Katepe-Bwalya M. Feeding practices and nutritional status of infants and young children in Mazabuka and Kafue Districts of Zambia. International Breastfeeding Journal. 2015;10(5). doi:10.1186/s13006-015-0033-x. Accessed March 2015.

33. Giashuddin M, Kabir M, Rahman A, Hannan M. Exclusive breastfeeding and nutritional status in Bangladesh. Indian J Pediatr. 2003;70(6):471-5.

34. Muchina E, Waithaka P. Relationship between breastfeeding practices and nutritional status of children aged 0-24 months in Nairobi, Kenya. African Journal of Food, Agriculture, Nutrition and Development. 2010;10(4):2358-78.

35. Kamudoni P, Maleta K, Shi Z. Exclusive breastfeeding duration during the first 6 months of life is positively associated with length-for-age among infants 6 - 12 months old, in Mangochi district, Malawi. 2014;69(1):96-101. http://www.ncbi.nlm.nih.gov/pubmed/25097000.

\section{Submit your next manuscript to BioMed Central and we will help you at every step:}

- We accept pre-submission inquiries

- Our selector tool helps you to find the most relevant journal

- We provide round the clock customer support

- Convenient online submission

- Thorough peer review

- Inclusion in PubMed and all major indexing services

- Maximum visibility for your research

Submit your manuscript at www.biomedcentral.com/submit
( Biomed Central 